\title{
A Case of COVID-19 Presenting with Posterior Reversible Encephalopathy Syndrome
}

\author{
Posterior Reversibl Ensefalopati Sendromu ile Prezente Olan COVID-19 Olgusu
}

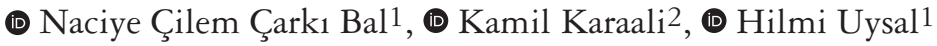 \\ ${ }^{1}$ Akdeniz University Faculty of Medicine Hospital, Department of Neurology, Antalya, Turkey \\ 2Akdeniz University Medical Faculty Hospital, Department of Radiology, Antalya, Turkey
}

Keywords: Reversible posterior leukoencephalopathy syndrome, encephalopathy, hypertensive, COVID-19, SARS-CoV

Anahtar Kelimeler: Reversibl posterior lökoensefalopati sendromu, ensefalopati, hipertansif, COVID-19, SARS-CoV

\section{Dear editor,}

A 28-year-old female patient without previous complaints was admitted to the emergency department with a sudden onset of blurred vision and headache upon waking up, without accompanying neurological complaints. She was 33-weeks pregnant. Visual acuity during neurological examination revealed that she could notice hand movements from a reading distance, and other neurological examinations, except the cerebellar tests, were normal. The eye fundus was normal. Blood pressure was $130 / 80 \mathrm{mmHg}$, body temperature was $36.4^{\circ} \mathrm{C}$, and pulse rate was 74 beats $/ \mathrm{min}$. She had a generalized tonic-clonic seizure lasting around $2 \mathrm{~min}$ while waiting for examination in the emergency department. The patient was given levetiracetam, and the seizure did not reoccur.

The brain magnetic resonance imaging (MRI) revealed T2-weighted fluid-attenuated inversion recovery (FLAIR) hyperintense lesions and intermittent foci located in the subcortical areas, in the posterior part of both the parietal and occipital lobes (Figure 1,2). No diffusion restriction that was compatible with acute-subacute infarction was observed in the diffusion-weighted apparent diffusion coefficient (ADC) and B1000 images. In both parietal lobes, more prominently on the left, cortical areas of increased intensity consistent with vasogenic edema were observed in the B1000 (Figure 3a). No obvious signal change was observed in the ADC images (Figure 3b). The hyperintensity level of T2

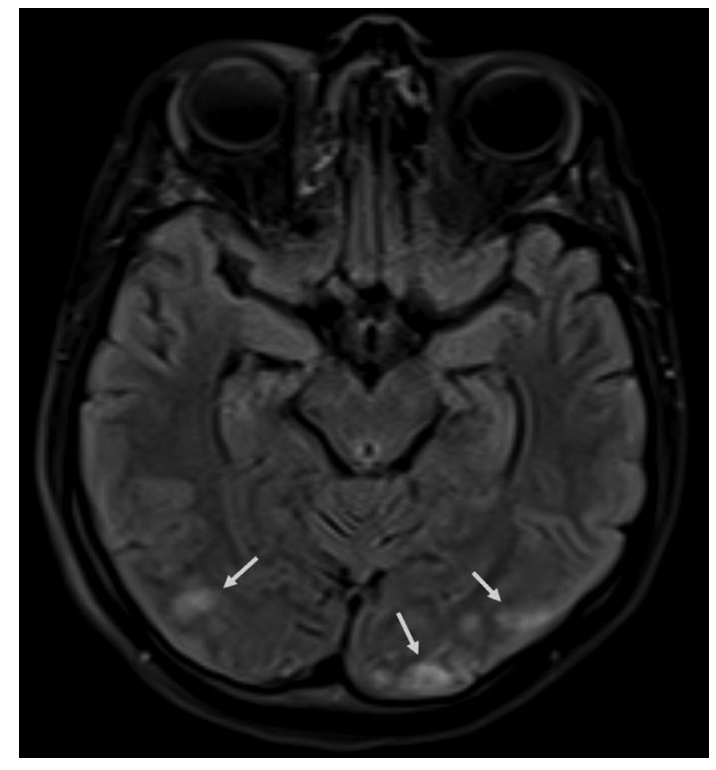

Figure 1. Axial brain MRI revealed T2/FLAIR hyperintense lesions and foci located in the subcortical areas, intermittently in the posterior part of both the parietal and occipital lobes

MRI: Magnetic resonance imaging, FLAIR: Fluid-attenuated inversion recovery

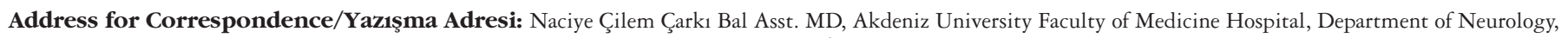
Antalya, Turkey

Phone: +90 2422496150 E-mail: ncc_1107@hotmail.com ORCID: orcid.org/0000-0003-0438-3718

Received/Geliş Tarihi: 28.10 .2020 Accepted/Kabul Tarihi: 11.07 .2021

${ }^{\circ}$ Copyright 2021 by Turkish Neurological Society

Turkish Journal of Neurology published by Galenos Publishing House. 


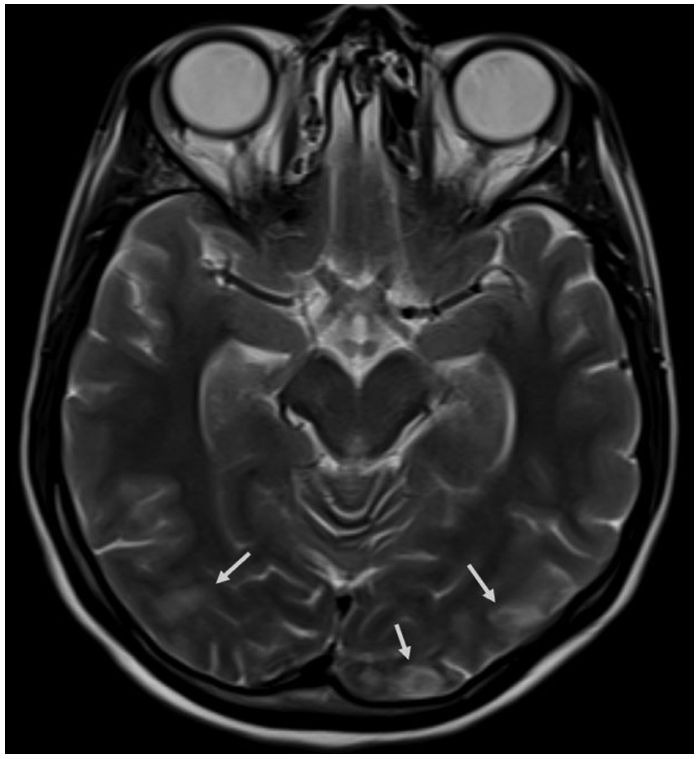

Figure 2. Axial MRI brain revealed T2-weighted image lesions and foci located in the subcortical areas, intermittently in the posterior part of both the parietal and occipital lobes

MRI: Magnetic resonance imaging

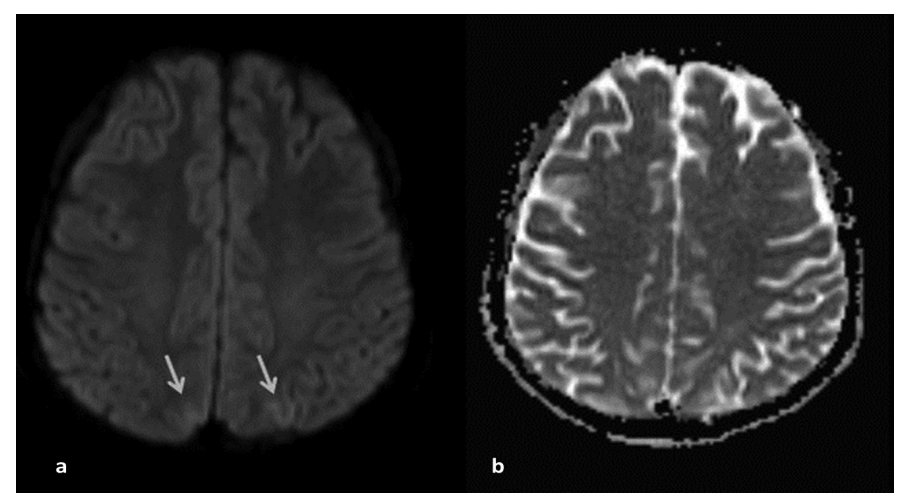

Figure 3. (a) In both parietal lobes and more prominently on the left, cortical areas of increased intensity consistent with vasogenic edema were observed in the B1000. (b) No obvious signal change in the ADC images ADC: Apparent diffusion coefficient

and FLAIR images did not match the level on diffusion MRI, and the lesion was observed in the diffusion-weighted images in the hyperintensity areas on $\mathrm{T} 2$ and FLAIR images. The finding in T2/FLAIR MRI was observed in a smaller area in the diffusion MRI. Kidney function tests and other blood tests were normal. Proteinuria was detected in the complete urinalysis.

The patient was admitted to the intensive care unit (ICU) due to a positive coronavirus disease-2019 (COVID-19) polymerase chain reaction $(\mathrm{PCR})$ test. The gynecology and obstetrics department evaluated the condition of the fetus and placed an indication for an emergency Cesarean section. The patient was monitored in the ICU after the operation, and the thoracic tomography was normal. The patient received favipiravir treatment and was clinically stable. While the patient was admitted to the ICU, a short-term intravenous antihypertensive treatment was given,

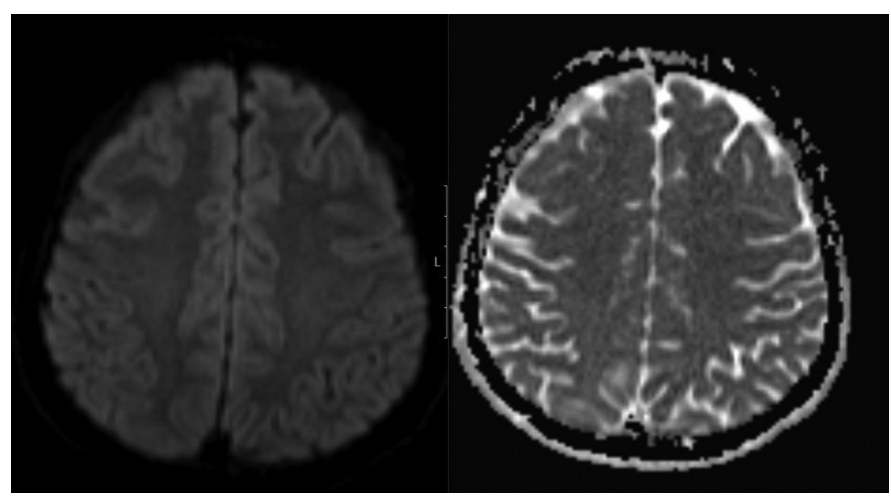

Figure 4. Intensities in the previous diffusion-weighted images completely disappeared in the same sections in the control MRI MRI: Magnetic resonance imaging

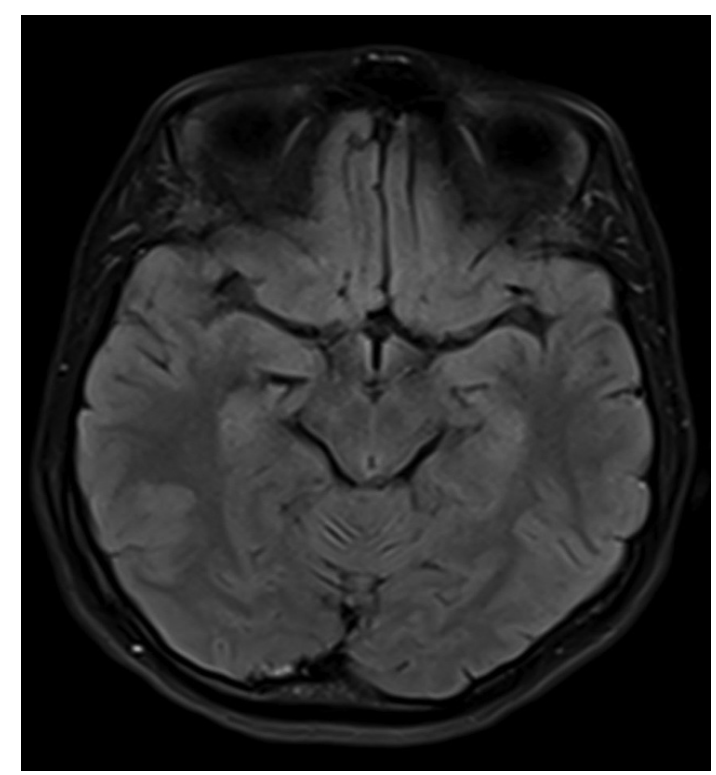

Figure 5. Intensities in the previous FLAIR image completely disappeared in the same sections in the control MRI

MRI: Magnetic resonance imaging, FLAIR: Fluid-attenuated inversion recovery

and blood pressure control was achieved with two different oral antihypertensive treatments. She was followed up with in the pandemic clinic for a week and discharged with antihypertensive treatment. After 2 months later, the patient's antihypertensive treatments were gradually discontinued since the patient was normotensive. Control MRI was normal after 5 months later. Intensities in the previous FLAIR/diffusion-weighted images disappeared completely in the same sections in the control MRI (Figure 4, 5).

The baby was born by Cesarean section at 33 weeks and was healthy, without the need for an incubator. Her COVID-19 PCR test was also negative.

COVID-19 causes neurological involvement as well as respiratory system problems. One of the reported neurological involvements is the posterior reversible encephalopathy syndrome 
(PRES) (1).

PRES is a neurological condition with an acute-subacute onset (24-48 h), which often causes symptoms such as blurred vision, seizures, consciousness changes, headache, nausea, and vomiting. The most common causes are hypertension, eclampsia and preeclampsia, renal failure, immune suppression, and cytotoxic drugs (2).

The most important tool in PRES diagnosis is the imaging method. The FLAIR and T2-weighted MR sections are especially used in the assessment of PRES. It is often symmetrical in the white matter, particularly in the parietal and occipital lobes. It can be observed in the frontal lobe, inferior temporal lobe, cerebral hemisphere, and rarely in the basal ganglion, brainstem, deep white matter, and spinal cord (3).

Its pathophysiology is unknown. The underlying mechanisms are the impairment of autoregulation due to acute hypertensive attacks and/or acute renal failure and blood-brain barrier disruption due to an endothelial dysfunction resulting from inflammation caused by COVID-19 or tocilizumab and anakinra intake $(4,5,6)$.

In the literature, the first admission complaints of COVID19-related PRES cases were mostly not neurological symptoms. The most common neurological complaints were impaired consciousness and seizures during hospitalization $(6,7)$. All cases were intubated and followed up with severe COVID-19 infection. Acute renal dysfunction and acute hypertensive attack due to COVID-19 infection are the most important factors in PRES development $(6,7,8,9,10,11,12)$. PRES cases were also reported to be due to cytotoxic effects of tocilizumab treatment $(8,10)$.

In our case, The reason for the development of PRES in our case; it was the result of autoregulation disorder due to severe COVID-19 infection. In addition, during the pandemic period, COVID-19 infection may be in a coincidental situation. COVID-19 infection should be considered among the causes of PRES during the pandemic period. Regardless of the cause, the definitive PRES diagnosis requires radiological correlation.

Ethics

Informed Consent: Permission was obtained from the patient. Peer-review: Internally peer-reviewed.

\section{Authorship Contributions}

Surgical and Medical Practices: N.Ç.Ç.B., H.U., Concept: N.Ç.Ç.B., H.U., Design: N.Ç.Ç.B., H.U., K.K., Data Collection or
Processing: N.Ç.Ç.B., H.U., Analysis or Interpretation: N.Ç.Ç.B., H.U., K.K., Literature Search: N.Ç.Ç.B., H.U., K.K., Writing: N.Ç.Ç.B.

Conflict of Interest: No conflict of interest was declared by the authors.

Financial Disclosure: The authors declared that this study received no financial support.

\section{References}

1. Mao L, Jin H, Wang M, et al. Neurologic manifestations of hospitalized patients with coronavirus disease 2019 in Wuhan, China. JAMA Neurol 2020;77:683-690.

2. Lamy C, Oppenheim C, Mas JL. Posterior reversible encephalopathy syndrome. Handb Clin Neurol 2014;121:1687-1701.

3. Bartynski W, Boardman J. Distinct imaging patterns and lesion distribution in posterior reversible encephalopathy syndrome. Am J Neuroradiol 2007;28:1320-1327.

4. Wu D, Yang XO. TH17 responses in cytokine storm of COVID-19: An emerging target of JAK2 inhibitor Fedratinib. J Microbiol Immunol Infect 2020;53:368-370.

5. Cai X, Bhattacharyya S, Plitt A, et al. Management of posterior reversible encephalopathy syndrome induced by carfilzomib in a patient with multiple myeloma. J Clin Oncol 2014;34:e1-e5.

6. Anand P, Lau KV, Chung DY, et al. Posterior reversible encephalopathy syndrome in patients with coronavirus disease 2019: two cases and a review of the literature. J Stroke Cerebrovasc Dis 2020;29:105212.

7. Ordoñez-Boschetti L, Torres-Romero C, De Leo MO. Associated posterior reversible encephalopathy syndrome (PRES) to SARS-CoV-2. Case report. Neurología (Engl Ed) 2020;35:696-698.

8. Kishfy L, Casasola M, Banankhah P, et al. Posterior reversible encephalopathy syndrome (PRES) as a neurological association in severe Covid-19. J Neurol Sci 2020;414:116943.

9. Cariddi LP, Damavandi PT, Carimati F, et al. Reversible encephalopathy syndrome (PRES) in a COVID-19 patient. J of Neurol 2020;267:31573160.

10. Parauda SC, Gao V, Gewirtz AN, et al. Posterior reversible encephalopathy syndrome in patients with COVID-19. J Neurol Sci 2020;416:117019.

11. Kaya Y, Kara S, Akinci C, Kocaman AS. Transient cortical blindness in COVID-19 pneumonia; a PRES-like syndrome: case report. J Neurol Sci 2020;413:116858.

12. Franceschi AM, Ahmed O, Giliberto L, Castillo M. Hemorrhagic posterior reversible encephalopathy syndrome as a manifestation of COVID-19 infection. Am J Neuroradiol 2020;41:1173-1176. 